\title{
Crystal Sand Table Media for Cerebral Palsy Student's Fine Motor
}

\author{
Indina Tarjiah, Haikal Bastian \\ Special Education, Faculty of Science Education \\ Universitas Negeri Jakarta \\ Jakarta, Indonesia \\ Indina.tarjiah@gmail.com, haikalbastian.80@gmail.com
}

\begin{abstract}
This research is aimed to produce a media product of Crystal Sand Table which can stimulate fine motor for students with Cerebral Palsy. This media development uses Borg and Gall's development procedure through the stage of data collection, planning, product development, validation, and trials. The validation is done by 3 experts; media expert, Cerebral Palsy expert, and material expert with $85 \%$ of success percentage. Crystal Sand Table media is tested to a student in class DII-1A in SLB D-D1 YPAC Jakarta. The result of this research shows that Crystal Sand Table media can be used to stimulate fine motor in the beginning stage of writing activity. Teachers are expected to be able to use Crystal Sand Table media in stimulating students in the beginning of writing activity.
\end{abstract}

Keywords—writing media; crystal sand table; cerebral palsy.

\section{INTRODUCTION}

There are many ways to express ourselves in communication, one of which is writing. Writing can be interpreted as one way to express a message you want to convey in shape of the graphic with symbols or letters, by using language that is easily understood and used in daily life. Writing is a complex process because it is an integrated activity of many abilities, such as conceptual ability and the motor visual perception that is affected by cognitive ability and the use of the fine motor, also the strength of competent hand muscles that can be felt when holding, cutting, and sticking.

Starting the process of writing is a skill that has to be mastered by students in elementary school. Before the process to writing, students must be introduced to the tools for writing and the way to use them. The way of initiating writing activity is taught to every student with no exception to students with special needs.

Students with special needs are individuals who have barriers and/or disturbances within themselves, in which those barriers and/or disturbances have been given aids, but still, they need special education services. Students with special needs have several categories such as physical and motor constraints.

Physical and motor constraints are individuals that have barriers to bones, joints, and muscular systems, which are primary or secondary that have impacts on adaptation, coordination, communication, mobility, and development disorder in meeting personal needs.
The barriers from cerebral palsy (CP) students with medium category are diverse, and these $\mathrm{CP}$ students are included in students with special needs with physical and motor constraints. They are actually accompanied by other disorders such as motor sensory disorder, thinking intelligence, cognition, perception, talking, and social-emotional disorders.

$\mathrm{CP}$ is a condition in which individuals experience abnormalities of non-progressive motion and posture, it is often accompanied by epilepsy and the inability to speak normally, diminished vision and intelligence, caused by developing brain lesions. CP with medium category is often characterized by barriers in mobility, movement and communication. The education and teaching process tend to vary according to $\mathrm{CP}$ student's ability.

Motion abnormalities are strongly affected by the site of the disorder in the brain. One of the disturbances is in the pyramidal tract which controls muscles to remain normal, if pyramidal tract doesn't function well in controlling the muscles, they will experience spastic and Mental Retardation (MR) which affect individual to be left behind in writing aspect.

The barrier of students with medium category of spastic diplegia cerebral palsy with MR is experiencing difficulty in doing fine motor activities. One of which is to begin the writing activity which will support students' learning process. The functions of writing for students are to copy, to take note, and to do their tasks given at school. Also, it is also to train the flexibility of their fine motor and to maintain the state of students with spastic diplegia cerebral palsy with MR.

The fine motor ability of a child with $\mathrm{CP}$ has small muscle disorders that require good coordination between motion and concentration. The process of initiating and beginning the writing activity is very important. In addition, the use of media to begin the writing is very limited. All this time, in initiating writing activity, SLB D YPAC Jakarta, especially the students with $\mathrm{CP}$ in grade 2, are only taught using the overall approach with the VAKT (Visual, Auditory, Kinesthetic, Tactile) method. The existing and used media to begin the writing activity have only been using simple tools, such as body lotion, paper, and sand with table and cardboard as the only pedestal. Based on observations made during the implementation of learning in class, observer found it less effective because the 
texture of body lotion was too greasy and there was no specific place to implement the lesson of how to begin the writing activity. On the other hand, other constraints such as economic constraint has resulted in no continuously implemented therapy to maintain the state of students, therefore, to avoid a setback in learning experienced by the students, it is necessary to make a learning media based on the students' condition.

In the early condition, students are able to move fine motor well enough. They have good controls of head and shoulder which allow the students to be stimulated, so they can also control elbow and wrist, fingers, stability, and distal motion or the end of the joint movement. In addition, teachers can make students familiar to hold a variety of object textures as well, ranging from slick, smooth, to rough.

Kemp states Media Learning is a tool that is prepared to maximize the effectiveness in delivering and completing a part of learning materials [1]. It can be concluded that the learning media is a tool that can be used in learning activities and educational media is a tool that is prepared to stimulate students in learning so as to facilitate students in understanding the material of the lessons taught. It can also make the learning process effective and efficient. And so can the development of this media, that will help maximize the work of fine motor muscle.

Daryanto states that the position of learning media is very important and can be seen in the picture below [2]:

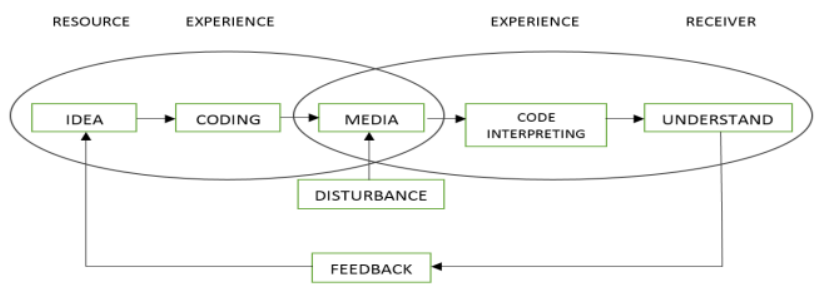

Fig. 1. The Position of Media in Learning System

The position of the media is in the middle, this explains that the media has an important role in overcoming students' existing disorders in the learning process. Writing is to paint the symbols in the form of graphics such as symbols or letters, using the language that is easily understood by the author and the language used in everyday life [3]. Writing is a tool of selfexpression [4]. Writing is a complex process because the ability to write is an integration of various capabilities such as the visual perception of the motor and conceptual ability that is influenced by cognitive ability. Writing is an act of expressing ideas, thoughts and feelings expressed in the language [5]. And from the description above, it can be concluded that writing is a way of communicating indirectly as well as a tool to pour ideas and thoughts in the form of writing.

TABLE I. ChILDS WRITING DEVELOPMENT

\begin{tabular}{|l|l|}
\hline \multicolumn{1}{|c|}{ Age } & \multicolumn{1}{c|}{ Childs Writing Ability } \\
\hline 10-12 months & Doodling irregular pattern \\
\hline 2 year & $\begin{array}{l}\text { Imitating horizontal line, vertical line, and circle on } \\
\text { paper }\end{array}$ \\
\hline 3 year & Coying horizontal line, vertical line, and circle \\
\hline
\end{tabular}

\begin{tabular}{|l|l|}
\hline \multicolumn{1}{|c|}{ Age } & \multicolumn{1}{|c|}{ Childs Writing Ability } \\
\hline 4-5 year & $\begin{array}{l}\text { Copying diagonal line to the right, the diagonal line } \\
\text { to the left, cross line, square, several letter and } \\
\text { number, and probably able to write his own name. }\end{array}$ \\
\hline 5-6 year & $\begin{array}{l}\text { Copying every triangle, writing his own name, } \\
\text { copying almost every capital and small letter }\end{array}$ \\
\hline
\end{tabular}

Some stages of development before the real act of writing is in kindergarten. However, grade 1 students write at the age of 5-6 years but this learning starts at the age of 2 years. The ability to control the limbs is needed in the implementation of writing and if the child is able to hold the stationery, then they can proceed with the writing process. Memory, coordinating and organizing visual functions into the motor, the use of dominant hands, and the ability to understand instruction can help the child and, at the same time, mey make it difficult if the child's perception is wrong.

Motoric thing is a latent event that covers the entire process of controlling and regulating the function of organs either physiologically or psychologically, which finally causes the happening of a motion. Motor development disorders are considered in the form of overflow movement when the child wants to move the right hand, the left hand follows. The move is accidental, lack of coordination in motor activity, and difficult in fine motor coordination, which is lack of body appreciation (body image), lack of understanding in spatial relations or direction, and laterality confusion [6].

From the above description, motor development disorder is characterized by several things, such as when one hand moves the other hand moves, then less coordination when doing the motor activity. Motor movement is less in accordance in doing the activity. Many of the imbalances make a child's motor skills disrupted. Based on some of the above description, it can be concluded that fine motor skills are when one can perform good coordination between fine motor with body language and spatial concept as well as doing fine motor exercise, if it is done as early as possible, it will help the child in any case. Also, learning sensory motor since the age of childhood is highly recommended to develop more complex cognitiveperceptual developments. Coaching the child's motor as early as possible will help the child in any case. And the cognitive abilities of children will be awakened from getting driven by both fine motor activity and gross motor.

As a result, the brain cannot develop, but that's not a progressive disease. In terms of pathological abnormalities occurance depending on the severity of the disorder or damage that occurs in the brain. The disorder is very complex, it can be local or comprehensive. The affected sites are generally the motor cortex area, the pyramidal tract, the basal ganglia, the brain shell and the cerebellum. The clearance of the central nervous system results in the form of a crucial abnormality since the muscles and spine are central to any coordination in the human body. According to the united cerebral research and educational foundation cited in [7], defines Cerebral Palsy as a clinical condition caused by injury to the brain. One component is a brain disorder. Thus, CP can be described as a condition characterized by a variety of motion, posture or body shape, coordination disorder, sometimes accompanied by 
psychological and sensory disorders caused by damage to the development of the brain.

According to the degree of functional loss, cerebral palsy is classified as (1) mild, with features that can walk without aids, clear speech, and can help themselves; (2) medium, with characteristics, need help for speech, walking, selfemployment, and special tools, such as brace; (3) heavy, with characteristics: that requires care but in ambulance, speech, and self-help. With the constraints and basic capabilities mentioned above, researchers want to develop the learning media by creating "Crystal Sand Table" to help the students with Spastic Diplegia CP with MR begin the writing activity

The use of crystal sand serves to stimulate children in fine motor exercises as a basic ability that must be possessed by children when they start to write because the fine sand texture allows the nerves stimulation of the hands when students grasp the sand. The table serves as a place or container in writing so the sand will not be scattered everywhere.

The glass is used to reflect the light from the lamp to optimize child's comprehension by utilizing visualization captured by the visual perception of Spastic Diplegia CP with MR students hoping that children can maintain information in the brain. With this mix of media components, it is hoped that students' constraints of Spastic Diplegia CP with MR who possesses fine motor obstacles in writing ability can be overcome.

\section{METHOD}

This research development strategy aims to produce products in the form of learning media that can stimulate the beginning of writing process so as to maintain the muscle state of CP learner's hand. The method used in making Crystal Sand Table is an innovative work. And the researchers follow the research steps of Borg and Gall that have been in accordance with the needs of researchers.

Respondents selected to test this innovative work are DII-A class students at SLB D-D1 YPAC Jakarta because the first fine-grained motor writing exercise is conducted at the elementary school level. Testing process of this product is done by 3 experts, they are material expert, media expert, and $\mathrm{CP}$ expert. The media expert involved will be undertaken by a lecturer working in the media, Ika Lestari, S.Pd., M.Sc., the material expert is performed by teachers of class DII-A namely Pra Setyaning Ayu, S.Pd., and CP expert is performed by special education practitioner, Agus S. Rakhman, M.Pd.

The development procedure conducted by the researcher has been modified to be in accordance with the needs, as follows:

- Data collection phase is done to acknowledge the need for the development of the field and literature study.

- The planning stage begins with the preparation of the initial design which will become the basic reference of the media. The planning stage of evaluating the media is done at this stage as well.
- The product development stage begins with collecting materials, materials processing, and it ends with the production of early product prototypes.

- Stage of validation and initial prototype media trial that have been produced will be validated twice, so that the media can be tested in the field to $1 \mathrm{CP}$ student.

The technique of data analysis conducted in this research is an expert review obtained by spreading opened and closed questionnaire to expert in which the open questionnaires will be in the description and the closed will be calculated by the formula (1) with $\mathrm{P}$ is results of answer, $\mathrm{f}$ is answered frequency and $\mathrm{n}$ is number of respondents.

$$
\mathrm{P}=(\mathrm{f} / \mathrm{n}) \times 100 \%
$$

And from the simple results it will obtain a percentage that can be interpreted in the form of quantitative according to the following criteria:

TABLE II. DATA ANALYSIS INTERPRETATION OF EXPERT REVIEWER ASSESSMENT RESULTS

\begin{tabular}{|l|l|}
\hline \multicolumn{1}{|c|}{ Assessment Categories } & \multicolumn{1}{c|}{ Value } \\
\hline $86 \%-100 \%$ & Very Good \\
\hline $70 \%-85 \%$ & Good \\
\hline $55 \%-69 \%$ & Fair \\
\hline Under $55 \%$ & Poor \\
\hline
\end{tabular}

The second assessment is done by doing Field Test. This assessment is done in the field to the finished media but requires some revision. Tests were conducted in class with observation sheets.

\section{RESUlT AND DISCUSSION}

The product name of this innovative development work is "CRYSTAL SAND TABLE". Crystal Sand Table Media is created and developed to stimulate fine motor for the beginning of learning to write for $\mathrm{CP}$ students. The media consists of a series of tables for laying sand, glass as a base for laying the sand as well as refracting the light from the built-in lamp with the control buttons on the left side of the table for the child's success indicator in maximizing fine motor, and sand as the media used in stimulating fine motor for the beginning writing activity.

Crystal Sand Table media product is also equipped with guidebooks of media use with language that is easily understood by teachers and users. In addition, Crystal Sand Table media also contains a material card intended for teachers and CP students to facilitate the stages of usage in stimulating fine motor to begin the learning of writing process.

This media has several advantages, including:

- This media can be used as a learning media for $\mathrm{CP}$ students' fine motor stimulus in the beginning of learning to write

- This media makes it easier for CP students to control their gestures because the material is strong enough to support the student's body 
- This media can improve the beginning writing skills

- This media uses a safe glass because it is made of acrylic material and not easily broken

- This media is equipped with a lamp indicator and a light switch as an indicator of success

- This media is equipped with a small door to remove sand when it finishes

- The inside of the media is equipped with a sand container

- This media increases the concentration of children

- This media involves the active role of CP students directly.

And the disadvantages of this media include:

- The use of this media should be adjusted to the user's circumstances

- The material is too heavy and not portable

- Acrylic glass is easily scratched and display less good impression

- When using acrylic, the light refraction is not optimal.

The development of Crystal Sand Table media refers to Borg and Gall's development model with simplification into 4 development steps. Among the stages is data collection, conducted to know the needs in SLB D-D1 YPAC Jakarta. Field studies were conducted by observing the barriers that existed in CP learners, then performing the analysis phase and continued with literature studies on the related theories. The second stage is the planning stage. At this stage, the crystal sand table media is at the preparation of the early design that will be the basis of the media. After that, grid assessment is made. The third stage is product development that begins with materials collection, processing, and production. The used materials include wood, sand, cable, lamp, battery, glass, and art paper. Then the last stages of validation and testing are conducted. Product validation results in an overall average of $85 \%$ and is considered good.

Subsequently, the field test. Based on the observations it can be concluded that the Crystal Sand Table can be used as a learning media to stimulate fine motor for the beginning of learning to write. In the product development of this model, what make the distinctions are the product conceptual outcome, product procedural results, and produce physical results.

The product conceptual results explain that Crystal Sand Table Media is formed based on the problems and facts gained during the collection of data and related theories that include the theory of Cerebral Palsy, Learning Media Theory, and Beginning the Writing Process Theory, which is incorporated and formed as the basis for making Crystal Sand Table media. The product development stage of product procedural results begins with materials collection, materials processing, and the last is production. Materials collected in the form of wood as the main material, and other materials, such as sand, acrylic glass, media cards, and lights to complement the media that has been planned. After the material is collected, the processing and the making is done by the researcher. And the ready-made table is ready to be validated and tested. Physical Results change the finished media consisting of a series of devices, from tables, sand, hint cards, to material cards.

\section{CONCLUSION}

Based on the exposure of the results and the discussion, it can be concluded that the media products produced in this study, Crystal Sand Table, is intended to stimulate fine motor for the beginning of writing process of students with Spastic Diplegia CP with Mental Retardation.

Crystal Sand Table media product development is validated by three experts; media expert, Cerebral Palsy expert, and material expert, with 2 times validation and the validation results have been revised in accordance with the input of three experts tested to the CP students of DII class in SLB D -D1 YPAC Jakarta. So, as the result, Crystal Sand Table media can be utilized as a media of sensory-motor learning in CP students in stimulating fine motor for beginning the writing process. Product Development of Innovative Works of Crystal Sand Table media can facilitate CP students because Crystal Sand Table learning media products developed in accordance with the characteristics of $\mathrm{CP}$ students who require a fine motor stimulus for beginning writing.

This research has an effect on the learning activity at SLB D-D1 YPAC Jakarta in the sensorimotor lesson which can be utilized in the fine motor development for the beginning writing of the students of CP Class DII-1B. It is expected that this media product can facilitate the teacher in overcoming sensorimotor problems, especially fine motor in the beginning of writing.

This research is also useful and has an effect on Student of Special Education Study Program that, with the existence of this research, it is expected to be a reference in developing the product on another specificity. From the exposure of various existing theories, data analysis, conclusions and implications that have been presented, the suggestions for teachers in this study are:

Crystal Sand Table media products can be used by teachers in solving fine motor problems in writing the beginning. With Crystal Sand Table media products, teachers are encouraged to be more passionate and creative in developing new learning media products. As for suggestions for further research next researcher is expected to continue this research, to see the success of the media in stimulating fine motor for beginning writing.

\section{REFERENCES}

[1] J. E. Kemp, and D. K. Dayton, Planning and producing instructional media, Harper \& Row. 1985.

[2] D. Daryanto. Media pembelajaran, Yogyakarta: Gava Media, 2010.

[3] A. Mulyono. Pendidikan bagi anak berkebutuhan khusus, Jakarta: Departemen Pendidikan dan Kebudayaan. 2006.

[4] M. Jamaris, Kesulitan belajar: perspektif, asesmen, dan penanggulangannya, Jakarta: Yayasan Penamas Murni, 2009.

[5] I. Rosidi, Menulis siapa takut (panduan bagi penulis pemula), Yogyakarta: Kanisius, 2009. 
[6] A.Mulyono, Pendidikan bagi anak kesulitan belajar, Jakarta: Departemen Pendidikan dan Kebudayaan, 2006.
[7] K. Irah, Pendidikan anak gangguan fisik dan motorik, Jakarta: LPP Pers Universitas Negeri Jakarta, 2015. 